\title{
Transnacionalização e transmidiação da ficção televisiva em países ibero-americanos
}

Maria Cristina Palma Mungioli

Professora doutora da Escola de Comunicações e Artes da Universidade de São Paulo, pesquisadora do Centro de Estudos de Telenovela (CETVN) e do Observatório Ibero-americano de Ficção Televisiva (OBITEL). Coordenadora do GP de Ficção Seriada da Intercom. E-mail: crismungioli@usp.br

Issaaf Karhawi

Mestranda em Ciências da Comunicação pela Escola de Comunicações e Artes da Universidade de São Paulo. Pesquisadora do Centro de Estudos de Telenovela (CETVN) e do Observatório Ibero-americano da Fiç̧ão Televisiva (OBITEL). Bolsista do CNPq.

E-mail: issaaf@usp.br

Resumo: A resenha apresenta alguns aspectos do Anuário Obitel 2012 - Transnacionalização da ficção televisiva nos países ibero-americanos, obra resultante de pesquisas desenvolvidas em onze países sobre a produção, exibição e circulação de programas de ficção. No presente texto, destacam-se dois dos assuntos tratados no anuário: a transnacionalização da ficção televisiva como marca de um atual quadro de trocas e fluxos no âmbito ibero-americano e a transmidiação da ficção televisiva, sobretudo nas redes sociais.

Palavras-chave: Ficção televisiva; Obitel; transnacionalização; transmidiação.
Abstract: This review presents the main points of the Obitel Yearbook 2012 Transnationalization of television fiction in Ibero-American countries (Transnacionalização da ficção televisiva nos países ibero-americanos) which shows the results of eleven countries researches about production, exhibition and circulation of their national television fiction. As the topic of the year, Obitel Yearbook 2012 observes transnationalization in television fiction as an important fact of the contemporary scenery of flows and exchanges within the Obitel scope.

Keywords: Television fiction; Obitel; transnationalization; transmedia.

\section{APRESENTAÇÃO}

O Observatório Ibero-americano da Ficção Televisiva (Obitel), em seu sexto anuário - Transnacionalização da ficção televisiva nos países ibero-americanos ${ }^{1}$-, apresenta um panorama da ficção produzida nos onze países integrantes do projeto (Argentina, Brasil, Chile, Colômbia, Equador, Espanha, Estados Unidos, México,

1. LOPES, Maria Immacolata Vassallo de; GÓMEZ, Guillermo Orozco (org.) Obitel 2012. Transnacionalização da ficção televisiva nos países ibero-americanos. Porto Alegre: Sulina, 2012. Disponível em: <www. obitel.net>. 
comunicação \& educação • Ano XVIII • número 1 • jan/jun 2013

Portugal, Uruguai e Venezuela). Coordenado por Maria Immacolata Vassallo de Lopes e Guillermo Orozco Gómez, desde 2005, o Obitel tem concentrado esforços na análise de, pelo menos, seis dimensões da ficção televisiva nos países que o integram: produção, exibição, consumo, comercialização, propostas temáticas e a recepção transmidiática. Além de, anualmente, eleger um tema ao qual dedica especial atenção; em 2012, a rede de pesquisadores analisou a transnacionalização da ficção televisiva.

Ao longo de 2011, cada um dos onze países acompanhou sistematicamente os programas de ficção de televisão aberta e, com base nos resultados desse monitoramento, elaborou um capítulo para compor o Anuário Obitel 2012.

No capítulo "Síntese comparativa dos países Obitel em 2011", os coordenadores do observatório dedicaram-se a analisar os dados de todos os países e compará-los, a fim de traçar um panorama geral do quadro de produção, circulação e consumo da ficção televisiva entre os países ibero-americanos do Obitel.

\section{A OFERTA DE FICÇÃO TELEVISIVA NOS PAÍSES IBERO-AMERICANOS}

Em meio a dados de número de estreias do ano, horários de exibição, número de capítulos/episódios, índices e perfil de audiência, o capítulo "Síntese comparativa dos países", do Obitel 2011, apresenta dados representativos em relação aos formatos das ficções. O Brasil e o México, por exemplo, foram os países que mais produziram telenovelas no âmbito Obitel no último triênio, com um total de 42 títulos cada, dado que evidencia não apenas a grande

2. Ibid.

3. 1o Passione (telenovela, Brasil); 2ㅇ Fina estampa (telenovela, Brasil); 3ㅇ Insensato coração (telenovela, Brasil); 4ㅇ A corazón abierto (série, Colômbia): 5ㅇ Ti-ti-ti (telenovela, Brasil); 6을 Morde \& assopra (telenovela Brasil); 70 El Joe la leyenda (telenovela, Colômbia) 8 Tres milagros (telenovela, Colômbia); 9으 Los 80; más que uma moda (série, Chile); 10 Cordel encantado (telenovela, Brasil).

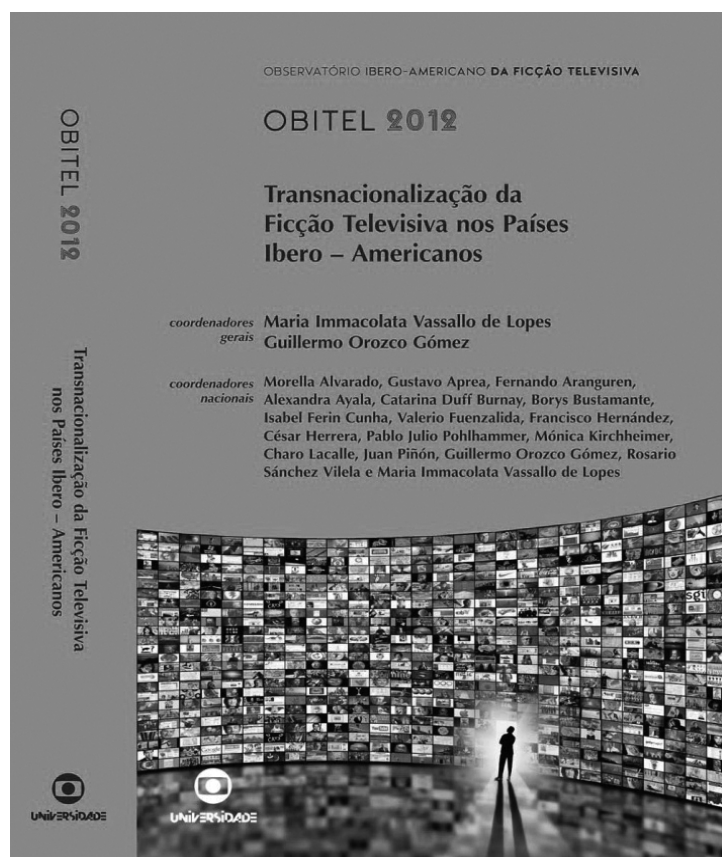

Capa do Obitel 2012 capacidade produtiva dos países, mas também a predileção entre os latino-americanos pelos formatos de longa serialidade como a telenovela. Por sua vez, a Espanha tem sido, nos últimos três anos, a maior produtora de séries e minisséries, confirmando “(...) uma particularidade do país, que, à diferença dos países latino-americanos, investe e se especializa fortemente em formatos de curta serialidade"2.

Com base nos índices de audiência das dez ficções mais vistas de cada país, o Obitel apresenta as 110 ficções televisivas mais vistas no ano. Entre os dez primeiros títu$\operatorname{los}^{3}$, seis são ficções brasileiras, três colombianas e uma chilena. Em relação aos formatos, observa-se 
que oito são telenovelas e dois, séries. As três primeiras posições do ranking são ocupadas por telenovelas brasileiras: Passione, Fina estampa, Insensato coração, resultado dos altos índices de audiência conquistados pela telenovela em nosso país, mesmo quando posta ao lado de outros países ibero-americanos que também se caracterizam pela produção e consumo de telenovelas.

\section{TRANSMIDIAÇÃO DA FICÇÃO TELEVISIVA: A CONVERSA DOS FÃS}

Antes de se dedicar ao tema do ano, a transnacionalização, o Obitel discute a transmidiação como ponto essencial na compreensão do atual panorama da ficção televisiva. Para Lopes et al. ${ }^{4}$ "o conjunto das mídias digitais vem consolidando processos e fenômenos de uma nova cultura de mídia, que estimula a interação dos produtos midiáticos e a convergência de conteúdos", fenômeno que proporciona transformações tanto na maneira de ver como na de fazer ficção.

No polo da produção, transformações podem ser percebidas, em menor ou maior escala, pela ocorrência de reestruturações nas narrativas que buscam atender às novas necessidades de consumo dos telespectadores envolvidos cada vez mais por novas plataformas. Os autores afirmam que “(...) a maioria das produções está levando suas narrativas para outras telas, principalmente para as do computador e do telefone celular, ambas em simbiose com a internet" o que exige renovações tanto na estrutura da narrativa (produção) quanto em sua circulação, distribuição e consumo.

Partindo da lógica proposta por Martín-Barbero, "o questionamento das novas tecnologias de comunicação nos obriga, assim, a analisar os diferentes registros desde os quais elas estão remodelando as identidades culturais" ${ }^{\prime \prime}$ (É nessa importância do registro da "nova cara" da ficção televisiva que os países do âmbito Obitel debruçaram-se sobre a questão da recepção transmidiática da ficção televisiva).

Compreender esse fenômeno exige não apenas um olhar lançado sobre o receptor, o internauta, o telespectador, mas também sobre o produtor transmidiático. É nesse sentido que os estudos do Obitel se concentram tanto no que os fãs de ficções televisivas produzem na internet, como também no que os produtores de ficção, as emissoras de televisão, estão disponibilizando para seu espectador. De acordo com Lopes e Orozco ${ }^{7}$ nas pesquisas de 2011 nota-se "[...] o investimento dos produtores para incorporar em seu relacionamento com a audiência as práticas dos fãs na internet e nas redes sociais [...] como forma de conseguir engajamento da audiência com suas produções".

Pensando no polo da produção (sites oficiais das ficções) entre os países do Obitel, de um lado estão Chile, Portugal e Uruguai, com uma baixa oferta transmidiática das dez ficções mais vistas em 2011. Em um plano intermediário, estão México, Colômbia, Equador e Venezuela, em patamares de crescimento da interação entre os espectadores e a oferta dos produtores. Como bons exemplos de grande oferta transmidiática por parte da produção das ficções, estão Espanha, Brasil, Estados Unidos e Argentina, "países que registram a maior
4. Lopes et al. Obitel 2010. Convergências e transmidiaçãoda ficção televisiva. São Paulo: Globo, 2010, p. 166

5. LOPES; OROZCO, op. cit., p. 49.

6. MARTÍN-BARBERO, Jesús. Ofício de cartógrafo: travessias latino-americanas da comunicação e cultura. São Paulo: Loyola 2004, p. 184.

7. LOPES; OROZCO, op. cit., p. 57. 
comunicação \& educação • Ano XVIII • número 1 • jan/jun 2013

8. LOPES; OROZCO, op. cit., p. 58.

9. JENKINS, Henry. Cultura da convergência. 2. ed. São Paulo: Aleph, 2009

10. JENKINS, op. cit.,p.33.

11. Conteúdo gerado pelo usuário, que nas análises refere-se à unidade de discurso das redes sociais (o post, ou postagem), seja ele composto apenas por textos, seja constituído de fotos, imagens ou vídeos.

12. LOPES, Maria Immacolata Vassallo de; GÓMEZ, Guillermo Orozco (org.). Obitel 2012. Transnacionalização da ficção televisiva nos países ibero-americanos. Porto Alegre: Sulina, 2012, p. 73. intensidade de interações entre fãs e produtores, que se realizam através das ofertas do emissor e das práticas da audiência"ষ.

$\mathrm{O}$ que define o processo de transmidiação da ficção televisiva de um determinado país não é um esquema fechado daquilo que deve ou não ser oferecido aos espectadores em um site de ficção, mas sim a relação que as emissoras de televisão estabelecem com seus fãs no ambiente virtual. Ou seja, o quanto o consumidor é cortejado ${ }^{9}$. Nas palavras de Jenkins ${ }^{10}$ ), "se o paradigma da revolução digital presumia que as novas mídias substituiriam as antigas, o emergente paradigma da convergência presume que novas e antigas mídias irão interagir de formas cada vez mais complexas". Portanto, os países que ofertam uma grande variedade de conteúdo transmidiático são aqueles em que os canais vêm tentando adequar-se mais rapidamente ao novo cenário de assistência de ficção não só nos países ibero-americanos, mas no mundo.

Outro aspecto importante do tópico de recepção transmidiática recai sobre a análise dos $\mathrm{CGU}^{11}$ dos internautas. O estudo busca compreender o que o fã produz na internet a partir das ficções televisivas, e não apenas o que lhe é oferecido pelo produtor. Dessa forma, destaca-se o que o telespectador fabrica, ou seja, o que ele absorve e o que faz com as horas que passa assistindo a programas televisivos, nesse caso, na internet.

Para acompanhar as conversas dos fãs sobre as ficções na internet, oito países monitoraram redes sociais como o Facebook, enquanto três outros buscaram CGU nos sites oficiais das ficções. A coleta reuniu mais de 68 mil CGU. Em uma categorização temática, a conversa dos fãs privilegiou a trama, os personagens, os atores, os roteiristas e produtores das ficções. Sob o ponto de vista das funções da linguagem de Jakobson, a função referencial e a emotiva são as mais proeminentes nos CGU dos espectadores ibero-americanos de ficção; a primeira, nas conversações sobre o capítulo do dia, horário de exibição, expectativas em relação ao enredo; a segunda, nas expressões de sentimentos despertados pela trama e na partilha de vivências do dia a dia.

Assim, os dados trazidos pelo Anuário Obitel 2012 mostram,, no que tange à recepção transmidiática, além de uma possibilidade metodológica para esse tipo de estudo ainda emergente, o lugar que a audiência televisiva tem ocupado nessa nova dinâmica midiática. Para Lopes e Orozco,

sem dúvida, há demonstrações da emergência de novos hábitos característicos de uma audiência participativa geradora de conteúdos [...] que toma em suas mãos a tarefa de criar espaços transmidiáticos para manifestação, debate e registro de sua experiência de fruição das ficções televisivas ${ }^{12}$.

\section{TRANSNACIONALIZAÇÃO NO ÂMBITO OBITEL: CAMINHOS DA FICÇÃOO TELEVISIVA}

O último tópico de análise do capítulo "Síntese comparativa dos países Obitel em 2011" apresenta o tema do ano adotado para o anuário 2012: a transnacionalização da ficção televisiva nos países ibero-americanos. 
Objetivamente, a escolha do tema almeja fazer um mapeamento dos fluxos transnacionais entre os países do âmbito Obitel. Pergunta-se: Quais são as atuais tendências de trocas na produção e distribuição da ficção?

Para os questionamentos acerca da transnacionalização, as discussões se baseiam nos estudos de Chalaby ${ }^{13}$. $\mathrm{O}$ autor "(...) descreve a nova ordem dos meios de comunicação transnacional como resultado de uma redesignação dos espaços, práticas, fluxos e produtos midiáticos”, ainda “(...) reconhece a emergência de uma nova ordem, com novas instituições midiáticas a nível regional, e o aumento do fluxo de populações, que tem feito aumentar o número e a visibilidade de audiências transnacionais" ${ }^{\prime 14}$.

A transnacionalização é caracterizada como um dos períodos de desenvolvimento mundial das mídias proposto por Chalaby ${ }^{15}$. Após a internacionalização e a globalização, a atual transnacionalização é definida por um cenário em que as relações entre o que é local, nacional, regional e global são reestruturadas pelas complexas redes de corporações midiáticas, produtos e audiências. Assim, temos que

[...] o transnacional permite reconhecer uma nova configuração, na qual jogadores emergentes interromperam a ideia de uma totalidade global midiática [...]. A emergência de um panorama de mídias mais "interdependente e assimétrico"16 é resultado do surgimento de instituições de mídia com impacto regional que permitiu questionar a ideia imperante de um sistema de relação unidirecional centro-periferia $[\ldots]^{17}$.

Levando-se em consideração os integrantes do Obitel, observa-se com clareza que enquanto uma parcela dos países - entre eles Brasil, México, Argentina, Colômbia, Espanha e Estados Unidos - é eminentemente exportadora, uma outra parcela, composta por Portugal, Chile, Uruguai, Venezuela e Equador, está essencialmente dirigida para seu mercado interno. Por ora, "essas diferenças [...] trazem elementos para explicar como estão sendo gestados os processos de transnacionalização [...], quais são as relações de poder que são impostas a partir das indústrias fortes e que tipo de estratégias adotam as indústrias emergentes para fortalecer seus mercados"18. O Brasil, por exemplo, tem uma produção de ficção $100 \%$ nacional entre os títulos mais vistos no ano (todos da Globo), o que o caracteriza como um caso especial no âmbito Obitel. Com um forte mercado interno de ficção nacional, o Brasil é reconhecido por suas narrativas que, apesar de inovarem, mantêm-se fiéis ao gosto nacional. Movimento que Wolton atribuiria à “(...) forte identidade cultural” do Brasil, país “(...) onde existe um mercado interior, [no qual se] percebem os riscos de dominação pelo estrangeiro e a ela opõem uma identidade e um voluntarismo nacionais" ${ }^{\prime 19}$.

Parcerias em coproduções e fluxos comerciais entre um país e outro são determinados, principalmente, por fronteiras físicas que propiciam ou dificultam as trocas, além de fatores linguísticos e proximidade cultural que "(...) estabelecem um marco para relações e dinâmicas particulares entre países de um determinado âmbito, como no caso de Brasil e Portugal e de todos os países hispânicos" ${ }^{20}$. Também determinam esses processos, os grandes exportadores
13. CHALABY, J. From internationalization to transnationalization. Global Media and Communication, v. 1, 1, p. 28-33, April 2005.

14. LOPES; OROZCO, op. cit., p. 73 e 74.

15. CHALABY, op. cit.

16. STRAUBHAAR, J.D. Beyond Media Imperialism: Asymmetrical Interdependence and CulturalProximity, Critical Studies in Mass Communication, 1991.

17. LOPES, Maria Immacolata Vassallo de; GÓMEZ, Guillermo Orozco (org.) Obitel 2012. Transnacionalização da ficção televisiva nos países ibero-americanos. Porto Alegre: Sulina, 2012, p. 74 .

18. LOPES; OROZCO, op. cit., p. 76.

19. WOLTON, Dominique. Elogio do grande público. São Paulo: Ática, 2006, p. 156.

20. LOPES; OROZCO, op. cit., p. 85. 
comunicação \& educação • Ano XV|l| • número 1 • jan/jun 2013

da área, como a própria Rede Globo (Brasil), a Televisa (México) e os norte-americanos Disney, Nickelodeon, MTV, HBO.

Ao longo do Anuário Obitel, outras questões servem de fio condutor à análise do cenário transnacional entre os países: Como se formam e se transformam os conteúdos da ficção televisiva nesse processo? Como essas trocas e fluxos medeiam e geram narrativas cultural e esteticamente novas? Aos países do Obitel, coube não apenas respondê-las, mas cumprir a valiosa missão de registrar o momento histórico, econômico e cultural das mudanças nas televisões ibero-americanas.

Por se tratar de um anuário, os dados e análises do Obitel 2012 devem ser lidos como parte de um discurso que engendra anteriormente: devemos entrar em uma correia de discursos anteriores que versam sobre pesquisas e procedimentos metodológicos discutidos ano a ano. Ainda, e mais substancialmente, a completude do anuário deve muito aos capítulos nacionais de cada país integrante do Observatório Ibero-americano da Ficção Televisiva, algo que não pudemos discutir devido aos limites deste artigo.

Na leitura da obra, é possível observar, em cada um dos onze países, os caminhos da ficção televisiva analisados sob o olhar de seus pesquisadores e de sua cultura em termos de ficção televisiva. Além disso, deve-se destacar que a publicação do Anuário Obitel, desde 2007, permite, ao estudioso da ficção e da televisão no espaço ibero-americano, o cotejamento de dados e informações valiosos para as pesquisas no campo da Comunicação.

\section{REFERÊNCIAS BIBLIOGRÁFICAS}

CHALABY, J. From internationalization to transnationalization. Global Media and Communication, v. 1, 1, p. 28-33, April 2005.

DE CERTEAU. Michel. Fazer com: usos e táticas. In: A invenção do cotidiano. V. 1. (Artes de fazer). Petrópolis/RJ: Vozes, 2007.

JENKINS, Henry. Cultura da convergência. 2. ed. São Paulo: Aleph, 2009.

LOPES, Maria Immacolata Vassallo de; GÓMEZ, Guillermo Orozco (org.). Obitel 2012. Transnacionalização da ficção televisiva nos países ibero-americanos. Porto Alegre: Sulina, 2012.

; MUNGIOLI, Maria Cristina Palma; BREDARIOLI, Claudia Maria Moraes; FREIRE, Denise de Oliveira; ALVES, Clarice Greco. Brasil - Novos modos de fazer e de ver ficção televisiva. In: LOPES, Maria Immacolata Vassallo de; GÓMEZ, Guillermo Orozco (org.). Obitel 2010. Convergências e transmidiação da ficção televisiva. São Paulo: Globo, 2010.

MARTÍN-BARBERO, Jesús. Ofício de cartógrafo: travessias latino-americanas da comunicação e da cultura. São Paulo: Loyola, 2004.

STRAUBHAAR, J.D. Beyond Media Imperialism: Asymmetrical Interdependence and CulturalProximity, Critical Studies in Mass Communication, 1991.

WOLTON, Dominique. Elogio do grande público. São Paulo: Ática, 2006. 